\title{
Metabolic Syndrome and Pregnancy, Its Prevalence, Obstetrical and Newborns Complications
}

\author{
Hamilton dos Prazeres Tavares ${ }^{*}$, Mariana Alvarez Arantes ${ }^{1}$, \\ Suelma Beatriz Marques Prata Tavares ${ }^{2}$, Joelcio Francisco Abbade ${ }^{3}$, \\ Débora Cristina Damasceno Meirelles dos Santos', \\ Iracema de Mattos Paranhos Calderon', Marilza Vieira Cunha Rudge ${ }^{5}$ \\ ${ }^{1}$ PhD Student in Gynecology, Obstetrics and Mastology at the Botucatu Medical School, Unesp, Paulista State \\ University, Botucatu, SP, Brazil \\ ${ }^{2}$ Medical Specialist in Gynaecology and Obstetrics and Boss of Department of Gynecology and Obstetrics of the \\ Municipal Hospital of Huambo, Huambo, Angola \\ ${ }^{3}$ Assistant Professor of Obstetrics, Botucatu Medical School, Unesp, Paulista State University, Botucatu, SP, \\ Brazil \\ ${ }^{4} \mathrm{PhD}$, Department of Gynecology and Obstetrics, Laboratory of Experimental Research on Gynecology and \\ Obstetrics, Botucatu Medical School, Unesp, Paulista State University, Botucatu, SP, Brazil \\ ${ }^{5}$ Full Professor of Obstetrics in Botucatu Medical School, Unesp, Paulista State University, Botucatu, SP, Brazil \\ Email: "hamitavares@hotmail.com
}

Received 18 August 2015; accepted 18 September 2015; published 21 September 2015

Copyright (C) 2015 by authors and Scientific Research Publishing Inc.

This work is licensed under the Creative Commons Attribution International License (CC BY). http://creativecommons.org/licenses/by/4.0/

(c) (i) Open Access

\section{Abstract}

Background: The metabolic syndrome affects more and more global people. Although it shows increasing prevalence in general population, the syndrome affects more women than men, what makes its risk of being developed during pregnancy period. Also, possible perinatal adverse effects are always lurking. Objective: the objective was demonstrated what's new in literature on metabolic syndrome and pregnancy. Methods: A literature review was performed to extract the articles published on metabolic syndrome and pregnancy, its prevalence, obstetrical complications and its perinatal adverse effects. This review was conducted by online researching in PubMed, Lilacs, Medline, Embase, Scopus, Medscape, Libertas Academica and CINAHL database, Science database and also by researches in books. 27 selected articles on metabolic syndrome after this research were all published between 1988 and 2015. Results: Among those 27 articles and two books studied, SM rate in obstetric population ranged from $3 \%$ to $42 \%$ depending on the previously manifested components of the syndrome, age and region. Women with previously manifested components showed more adverse perinatal effects. Conclusion: Women with pregesta"Corresponding author. 
tional DM or SM and SM develop more during pregnancy, obstetric complications and adverse perinatal outcomes.

\author{
Keywords
}

Metabolic Syndrome, Pregnancy, Adverse, Perinatal Outcomes

\title{
1. Introduction
}

Metabolic syndrome (MS) is a complex disorder that affects more and more people nowadays. It's considered as an epidemic of the $21^{\text {st }}$ century. Nowadays, it's a cause for concern in both today, considered as an epidemic of XXI century. Today, it is a matter of concern in both developed and developing countries [1].

MetS was first described as a syndrome by Reaven in 1988 [2]. With the increasing worldwide prevalence of obesity and MS, pregnant women with preeclampsia have many of the characteristics of MS, which makes it a provocative subject [3].

The prevalence of MS is commoner in females and increases with the age and urban housing [4].

It is associated with the rising incidence of obesity in developed and developing countries and is reaching epidemic proportions affecting between $24 \%$ and $34 \%$ of the US population and up to $36 \%$ of Europeans aged 40 55 years [5].

In a recent study in Greece, the prevalence of metabolic syndrome was $25 \%$ in adult men and $15 \%$ in women according to the National Cholesterol Education Program, Adult Treatment Panel III [6].

Metabolic syndrome is not a universally-accepted entity and, although certain cardiovascular risk factors undoubtedly occur together more often than expected by chance, the underlying pathophysiology of the syndrome is unclear [7]. However, so far several definitions have been proposed [8], namely by the World Health Organization (WHO), the International Disease Federation (IDF), the National Cholesterol Education Program (NCEP), and the fourth was the modified definition of the NCEP/ATP III (ATP III/ American Heart Association (AHA)/ National Heart, Lung and Blood Institute (NHLBI)) [1] [2]. Among these, the report of the panel of NCEP called “Adult Treatment Panel III (ATP III)" has been widely used as a common definition in literature [9]-[11]. Now, the JIS proposed is frequently used when we couldn't find metabolic syndrome [12].

The ATP III method for diagnosing MetS is the presence of three or more of the five criteria-emphasis on high waist circumference (WC $>102 \mathrm{~cm}$ in men and WC $>88 \mathrm{~cm}$ in women), high blood pressure (BP $>130 / 80$ $\mathrm{mm} / \mathrm{Hg}$ ), high triglyceride (TG $>150 \mathrm{~mm} / \mathrm{dl}$ ), high glucose (FBG $>110 \mathrm{mg} / \mathrm{dl}$, and low HDL (HDL $<40 \mathrm{mg} / \mathrm{dl}$ in men and HDL $<50 \mathrm{mg} / \mathrm{dl}$ in women) [2]. On the other hand, abdominal obesity, defined by high WC is a compulsory criterion on two or more of the other four criteria in IDF definition [11].

SM is defined by an interconnected set of factors that directly increases the risk of cardiovascular diseasecoronary heart disease (DCC), other forms of atherosclerotic cardiovascular disease (CVD) and metabolic diseases (diabetes mellitus type 2 (T2DM)).

Its main components are: dyslipidemia, characterized by elevated triglycerides and apolipoprotein B (apoB), containing lipoproteins, low and high density lipoproteins (HDL cholesterol), elevated blood pressure (BP) and hyperglycemia, abdominal obesity and/or insulin resistance (IR).

As the research was developed, other abnormalities have been found in people with this syndrome such as pro-inflammatory state, pro-thrombotic non-alcoholic fatty liver disease and sleep apnea [13].

In the United States, about a quarter of the adults suffer from Metabolic Syndrome [14].

The SM setting in pregnancy is controversial because the criteria for detection of SM overlap to the physiologic changes of pregnancy. During pregnancy, a woman experiences a set of periodic transformations that disappear after delivery, among many quoted phenomena: insulin resistance, increased anabolism in the first half of pregnancy, increased adiposity, hyperlipidemia, prothrombotic state [15]. Studies published on Diabetes Care, shows that women who have not lost the weight gained during pregnancy up to twelve months after the birth of the baby or put up on weight at this stage, are at serious health risks [16].

The role of insulin resistance in the pathophysiology of pregnant women with SM components (pre-eclampsia, eclampsia, gestational diabetes) or even SM allow healthcare professionals to intervene properly and on time in 
pregnant women to prevent obstetric and neonatal disasters.

The prevalence of SM markers (obesity, high levels of glucose, triglycerides, total cholesterol and LDL cholesterol) shows increasing trend with the evolution of pregnancy.

There are various diagnosing criteria for metabolic syndrome, but just Bartha and Chatzi presented modifications to diagnosis of the metabolic syndrome in obstetric people. Bartha introduced changes to the criteria of WHO and NCEP-ATP III, while Chatzi did it in the criteria of the NCEP ATP III and the NHLBI/AHA [17] (Table 1 and Table 2).

In 2009, Chatzi et al. also submitted proposals for diagnosis of metabolic syndrome in obstetric population. Based on the NCEP ATP III and on the NHLBI/AHA criteria, waist circumference is not considered as obesity and neither criterion. While obesity is defined as a body mass index greater than CERTAIN = pre-pregnancy > $30 \mathrm{~kg} / \mathrm{m}^{2}$-, in particular, metabolic syndrome is diagnosed if 3 or more of the following risk factors are present: pre-pregnancy body mass index $>30 \mathrm{~kg} / \mathrm{m}^{2}$; level of triglyceride $\geq 150 \mathrm{mg} / \mathrm{dL}$; cholesterol level $\mathrm{HDL}<50$ $\mathrm{mg} / \mathrm{dl}$; fasting plasma glucose level $\geq 100 \mathrm{mg} / \mathrm{dL}$, and blood pressure level $\geq 130 / 85 \mathrm{~mm} \mathrm{Hg}$ [18]-[19].

Metabolic alteration in pre-pregancy is a determinant complication factor in pregnancy, post-pregnancy, in life after birth and adverse perinatal outcomes. High maternal before pregnancy increased the risk of adverse pregnancy outcomes, obesity has been demonstrated to be an independent risk factor for: macrosomia, delivery by cesarean section, pregnancy induced hypertension, congenital malformation and lead to fetal death [20].

The diagnosis of MS during pregnancy identifies women at increased risk for developing cardiovascular and metabolic complications later in life and that are potentially candidate to develop pathologies related to pregnancy, making it a proper situation to evaluate the perinatal adverse effects [21].

\section{Table 1. NCEP-ATP III adaptation of MS settings to pregnancy.}

\begin{tabular}{|c|c|}
\hline Clinical NCEP_ATP III for defining SM & $\begin{array}{l}\text { Proposal for Adaptation of MS definition of the NCEP-ATP III to preg- } \\
\text { nancy [15] }\end{array}$ \\
\hline Any of the following 3 & Any of the following 3 \\
\hline $\begin{array}{l}\text { Visceral obesity, defined as waist circumference }>88 \mathrm{~cm} \\
\text { (in women) }\end{array}$ & $\begin{array}{l}\text { Visceral obesity, defined as waist circumference }>2 \text { SD for gestational } \\
\text { age in the } 1^{\text {st }} \text { half of pregnancy or pre-pregnancy BMI }>30 \mathrm{~kg} / \mathrm{m}^{2}\end{array}$ \\
\hline Plasma triglycerides $\geq 150 \mathrm{mg} / \mathrm{dl}$ & Plasma triglycerides $\geq 2$ SD for gestational age \\
\hline$<$ HDL cholesterol 50 mg/dl (in women) & HDL cholesterol $<2$ SD for gestational age \\
\hline Blood Pressure $\geq 130 / \geq 85 \mathrm{~mm} / \mathrm{Hg}$ & Blood Pressure $\geq 130 / \geq 85 \mathrm{~mm} / \mathrm{Hg}$ \\
\hline Fasting glucose $\geq 110 \mathrm{mg} / \mathrm{dL}$ & Fasting glucose $\geq 110 \mathrm{mg} / \mathrm{dL}$ \\
\hline
\end{tabular}

\section{Table 2. WHO adaptation of MS settings to pregnancy.}

\begin{tabular}{|c|c|}
\hline WHO clinical criteria for defining SM & Proposal for Adaptation to Pregnancy SM definition of WHO [15] \\
\hline Resistance to insulin by one of the following & Resistance to insulin by one of the following \\
\hline Type 2 Diabetes & Type 2 Diabetes \\
\hline Impaired fasting glucose & Impaired fasting glucose $\geq 105 \mathrm{mg} / \mathrm{dL}$ \\
\hline Impaired Glucose Tolerance & - \\
\hline $\begin{array}{l}\text { Insulin resistance defined euglycemic hyper- } \\
\text { insulinemic clamp using the }\end{array}$ & $\begin{array}{l}\text { Insulin resistance defined using the euglycemic hyperinsulinemic clamp or other } \\
\text { sensitivity measuring method insulin, adjusted for gestational age }\end{array}$ \\
\hline More any two of the following & More any two of the following \\
\hline $\begin{array}{l}\text { Antihypertensive and/or high blood pressure } \\
\text { (systolic or diastolic } \geq 140 \geq 90 \mathrm{~mm} / \mathrm{Hg} \text { ) }\end{array}$ & Antihypertensive and/or high blood pressure (systolic or diastolic $\geq 140 \geq 90 \mathrm{~mm} / \mathrm{Hg}$ ) \\
\hline Plasma triglycerides $\geq 150 \mathrm{mg} / \mathrm{dl}$ & Triglicerídeos plasmáticos $\geq 2$ DP para a idade gestacional \\
\hline$<$ HDL cholesterol 39 mg/dl (in women) & Cholesterol HDL $<2$ DP for gestational age \\
\hline $\begin{array}{l}>\text { BMI } 30 \mathrm{~kg} / \mathrm{m}^{2} \text { and } / \text { or the waist } / \mathrm{hip}>0.85 \\
\text { (in women) }\end{array}$ & IMC pre-pregnancy $>30 \mathrm{Kg} / \mathrm{m}^{2}$ and/or waist/hip ratio $>0.85$ \\
\hline $\begin{array}{l}\text { Urinary albumin excretion rate } \geq 20 \mathrm{~g} / \mathrm{min} \text { or } \\
\text { albumin creatinine ratio } \geq 30 \mathrm{mg} / \mathrm{g}\end{array}$ & - \\
\hline
\end{tabular}


Women with MS have a higher risk of developing GDM and because of that they can develop about 30\% risk for future development of diabetes type 2 (DM2) [22].

There are few studies on metabolic syndrome in pregnancy. In pregnant women with GDM it was reported a prevalence of $10 \%$ [17]-[24]. In pregnant adolescents, the prevalence is 3\% - 5\% [25]. Women with gestational hypertension have increased risk for developing insulin resistance postpartum, thus increasing likelihood of developing the metabolic syndrome. Drebes et al. 2009 detected a prevalence of MS in puerparas who had been diagnosed pre-eclampasia of $13.9 \%$, [26] 7.6\% [27].

In Brazil, a PhD thesis developed in the PG Program in Gynecology, Obstetrics and Mastology (PGGOM) at Unesp by Negrato et al. in 2008 found 24\% to 36\%, while another study conducted by Drebes [26] "Disease Gestational Hypertension and Metabolic Syndrome" in Pontifical Catholic University of Rio Grande do Sul, found $42 \%$ pregnant women with MS [26].

Once diagnosed Metabolic Syndrome in Pregnancy (MSG) or elements of it, it's possible to provide rapid intervention to prevent complications in pregnancy and adverse perinatal outcomes [28].

Maternal dietary conditions and changes in the intra uterine environment are directly related to the outcome of pregnancy. Childbirth preterm, restricted intra uterine growth and newborn with low weight have a higher risk of developing cardiovascular disease and insulin resistance in the future. Previous studies have reported associations between pre-pregnancy obesity, chronic hypertension, dyslipidemia, and inflammation in early pregnancy to higher risks of preterm birth and intrauterine growth restriction [18].

\section{Perinatal Adverse Effects}

Concerning the adverse perinatal outcomes, the LGA and SGA neonates have augmented chances of developing metabolic syndrome later [29].

The nourishment of the mother, of the embryo, of the fetus and of the newborn, plays an important condition for a generation in developing or not diseases in future life. Lifestyle and feeding characteristics such as being natural, synthetic, with or without pesticides etc. are directly related to ontogeny and diseases development [19].

Pregnant women with metabolic syndrome components are still considered at high risk despite all the scientific efforts that have occurred along the years to promote quality more and more. Yet, the control of this is lower than desired. Thus, perinatal adverse effects (malformations, neonatal, neonatal hypoglycemia, and neonatal macrosomia jaundice) continue to increase and this increase is directly proportional to the values and Components numbers of MS presented [30].

Pregnant women with "insulin dependent DM" give birth to offspring with risk two to three times superior than the normal rate of having malformation, whereas this risk is not observed in pregnant women with gestational diabetes. Multiple malformations are more frequent in diabetics' offspring than in nondiabetics [22]. The macrosomia newborns have increased rate of hypoglycemia, hyperbilirubinemia, hypocalcemia, respiratory distress syndrome and hypertrophic cardiomyopathy [22].

The high levels of maternal glycemia lead to fetal hyperglycemia, and then to hyperglycemia in both mother and fetus. Subsequently, the augmented insulin production occurred as an attempt of metabolism of the available glycosis, causes hypertrophy and hyperplasia of pancreatic b-cells.

Hyperinsulinemia and hyperglycemia in the intrauterine environment is common in pregnancies complicated by diabetes, what cause bigger fetal organs development than they should be and therefore favors the emergence of macrosomia. Moreover, the excessive and continuous supply of glucose, amino acids and lipids from the mother to the fetus stimulates the increase of newborn weight. Other determinant factors of fetal growth and additional elements such as the presence of some hormones triglycerides, of free fatty acids, ketones, leptin, amino acids and growth factors insulin-like (IGF) and insulin, are recognized as causative agents of exacerbated fetal development [30].

Many studies refer to BMI bigger than $25 \mathrm{~kg} / \mathrm{m}^{2}$ interference with parturition birth weight greater than 4000 grams. Other studies make reference to the fact that the pre-gestational hyperglycemia and hyperinsulinemia in the first trimester of pregnancy might be associated with macrosomia. Pregnant women with hyperglycemia in the first quarter, when out of control, have increased in five times the risk of developing macrofeto [22].

Hyperglycemia harms the PAX gene-3, which is responsible for the closure of the neural tube. The oxygen free radicals concentration increases because of hyperglycemia and this can have teratogenic effects. Fetal lungs also suffer with this situation and may develop respiratory distress syndrome $(20 \%-30 \%)$ due to the fact that 
the hyperglycemia and hyperinsulinemia retard fetal lung maturity [31].

Fetal macrosomia is linked to perinatal complications such as: maternal morbidity, trauma at birth, fetal distress during labor (25\%), neonatal hypoglycemia (8\% - 22\%), hiperbilurrubinemia (15\% - 20\%) and neonatal mortality [31].

The hiperinsulinemia inhibits the action of cortisol in the lung, what leads to lecithin inhibition production by type II pneumocytes. Lecithin is a fosfolipideo present in the surfactant, which stabilizes the pulmonary alveoli during the expiration. Its decrease leads to the syndrome of respiratory discomfort, SRD [32].

The neonatal hiperbilurribunemia, defined as bilirubin bigger than $13 \mathrm{mg} / \mathrm{dl}$ complicates the evolution of newborns in $20 \%$ of diabetic mothers and infants. Polycythemia and hyperbilirubinemia set a situation in $3 \%-5 \%$ of diabetic mothers and infants. Diabetic pregnancy causes an increase in viscosity, providing clinical sequelae such as heart failure, renal impairment, renal vein thrombosis, necrotizing enterocolitis and damage to the central nervous system, leading to decreased blood oxygenation and stimulation of erythropoiesis [32].

Congenital malformations are commonly more frequent and severe in children born of pregnant women who have gestational diabetes than in the population without this condition. The most common kinds of malformation are: anencephaly, spina bifida, hydrocephalus, rectal/anal atresia, renal anomalies, cardiac hypertrophy, organomegaly and increase in blood volume. These are all associated with gestational diabetes. It's worth recalling that children of diabetic mothers have a higher risk of later obesity and often are in obesity class III; they also develop diabetes and problems in psychomotor development [33]. Regarding the obstetric and neonatal complications related to MS in pregnancy, gestational diabetes, hiperisulinemia, presence of acute co-morbidities or chronic complications are directly related to morbidity and maternal and fetal mortality. For this association is urgent to pay more attention in the treatment and diet to prevent diseases that cause disorders in the lives of mother/fetus and society. $50 \%$ to $70 \%$ of diabetic pregnant women improve their glycemic rates with dietary improvement [34].

\section{Methodology}

We reviewed the literature to demonstrate the current state of metabolic syndrome and pregnancy, its prevalence, obstetric complications and its adverse perinatal factors. To support this review, surveys were conducted in 27 articles and in two books of obstetric publications from 1988 to 2015. PubMed, Lilacs, Medline, Embase, Scopus, Medscape, Libertas Academica, CINAHL and Science databases were used to search for articles published on metabolic syndrome in pregnancy. We searched all those databases using the key words: metabolic syndrome in pregnancy, the MS prevalence in pregnancy, perinatal adverse effects in pregnant women with MS. 71 articles published in English and Portuguese were identified.

All the identified articles were reviewed to find and avoid possible duplication and then arranged for further survey. By analyzing the titles of the articles, the ones whose design differed from inclusion criteria (metabolic syndrome in pregnancy, adverse perinatal outcome) were excluded. Summaries of the articles were read and selected and we excluded those which did not mention the features of metabolic syndrome in pregnancy and its adverse perinatal outcomes. The complete text of selected articles were retrieved and reviewed independently. After data extraction, a new review of articles was made as a means to ensure that the data of the selected articles were included only once in the analysis, which resulted in only 27 remaining articles taking part with this review.

The results are summarized according to sample size, type of study, the definition used for metabolic syndrome in pregnancy and its prevalence. Risk factors were also evaluated. From all of these studies, 27 articles focused mainly on the syndrome definition, its prevalence and its adverse perinatal outcomes (Figure 1).

\section{Results}

Women with pre gestational metabolic syndrome are more likely to develop complications during pregnancy, such as pre eclampsia, eclampsia, gestational diabetes, and coma. Thereby increasing the possibility of being born a baby with perinatal adverse effects such as malformations, hypoglycemia, macrofeto among others, while when this syndrome begins in pregnancy, reduce the harm chances formations because they have relationships with situations that occur in the first quarter pregnancy, with only the chances of having obstetric complications and with respect to the newborn: Macrofeto, jaundice, hypoglycemia and respiratory distress syndrome. 


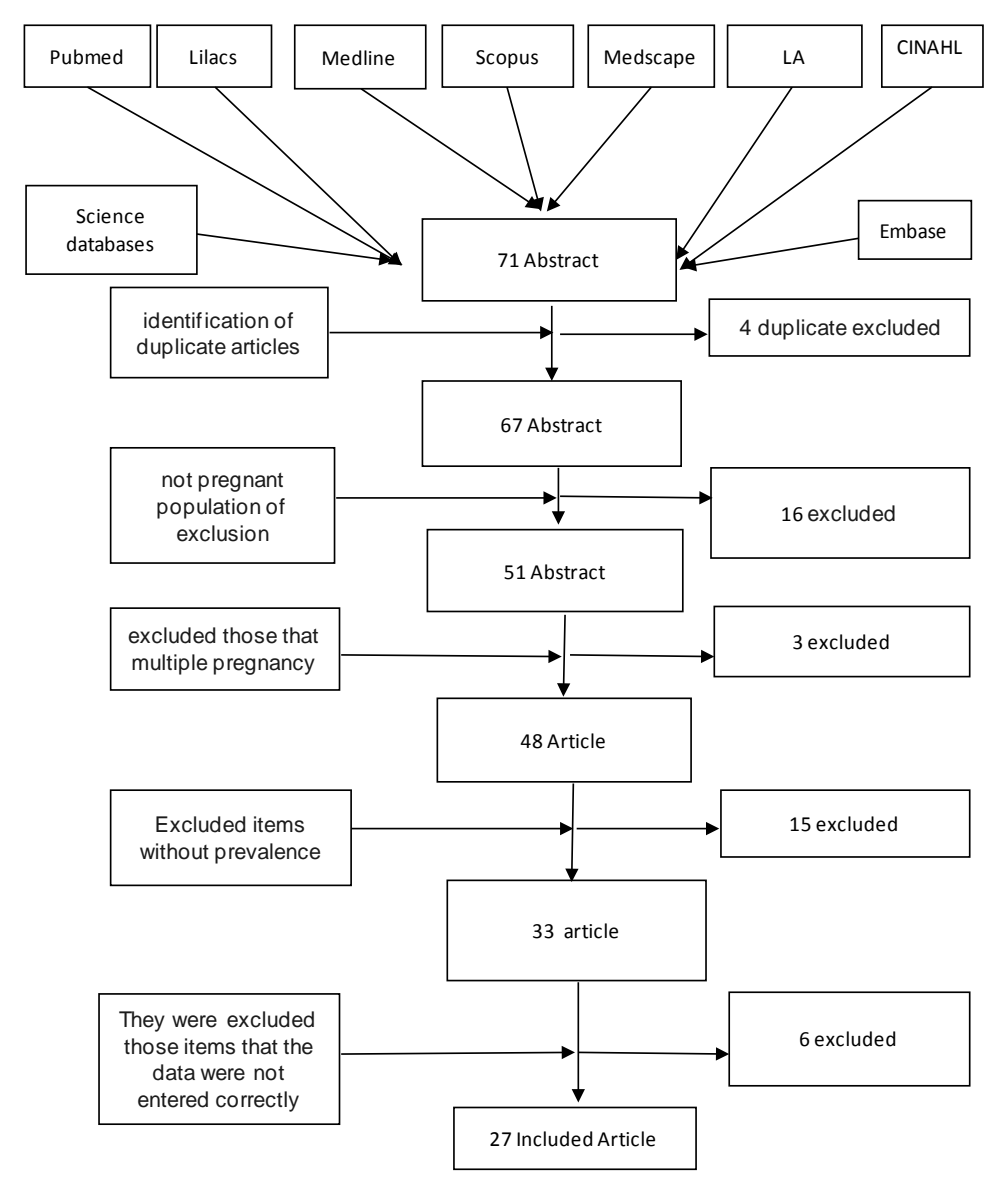

Figure 1. Search strategy.

\section{Recommendation}

Metabolic syndrome is an entity that must be diagnosed early so you can provide an opportunity for health professionals to intervene in ways to promote health and prevent complications.

\section{Our Experience at the Experimental Laboratory of Gynecology and Obstetrics of Botucatu Medical University/Universidade Estadual Paulista}

The unprecedented identification of pregnant women with mild gestational hyperglycemia-HGL (using the following diagnostic tests: Tolerance Test to normal glucose and glycemic profile changes, proposed by RUDGE, are now recognized by the international literature (HAPO, It was performed by the Diabetes Research Group and Pregnancy: Clinical \& Experimental Research from CNPq) which started in 1983 at the Botucatu University of Medicine/UNESP. In the early projects and publications, the name of this group of pregnant women with abnormal glucose profile was IB of Rudge. Research related to these IB groups of mothers who have HGL, correspond to $13.8 \%$ of the pregnant women with positive screening for GDM, which added to $7.0 \%$ of the pregnancies complicated by diabetes and augmented the occurrence of hyperglycemic disorders in pregnancy to about 20\%. The translational research has guided all the researches over the years (SGARBOSA et al., 2006; RUDGE et al., 2006, 2007, 2009; CALDERON et al., 2007; CAMPOS et al., 2007, 2008; LIMA et al., 2007; SPINNATO et al., 2008; SIBAI et al., 2008; VOLPATO et al., 2008, 2009; NEGRATO et al., 2008, 2009; DE LUCA et al., 2009; de SOUZA et al., 2009, 2010; PIETRO et al., 2010). Investigations have shown that pregnant women with HGL and DMG have several clinical parameters of MS during pregnancy. The history of DMG (odds ratio 3.75; IC 95\% 1.03 - 15.9), and BMI $\geq 25 / \mathrm{kg} \mathrm{m}^{2}$ (odds ratio 3.63; IC 95\%; 1.06 - 12.49) was more relevant for MS occurrence during pregnancy. Determinations HOMA-IR and HOMA- $\beta$ indicated in pregnant women with HGL, an insulin resistance framework that persists 06 weeks postpartum and that asso- 
ciates pregnant women with GDM directly to the occurrence of MS during pregnancy [22].

Pregnant women who developed GDM or HGL usually were found to be born with lower weight and shorter legs, showing the fetal programming of MS still in their intrauterine life. Nowadays, literature alerts to the risks of association between MS and its components in pregnancies complicated by GDM or HGL Negrato et al., (2008), suggesting strong interrelationship between these conditions. Since there was no global definition for MS during pregnancy, Negrato et al., in 2008, adopted the following criteria: any of the three primary criteria (changes in glycemic profile and/or the GTT or hyperinsulinemia) plus at least two of the following criteria: hypertension, dyslipidemia and obesity. The results showed that MS components had great impact on the product of conception, increasing the adverse perinatal events-APO (Adverse Perinatal Outcome). The prevalence of MS during pregnancy increased with worsening of glucose tolerance, reflected insulin resistance/hyperinsulinemia leading to increased fetal weight and was precursor of adverse perinatal outcome (APO). The diagnosis of MS in the second half of pregnancy was an important indicator of fetal macrosomia in both DMG and HGL, showing that the sum of MS components identifies a group of high-risk pregnant women about to develop APO [22].

The results strongly recommend that people with MS during pregnancy need to be compared to the population of other countries in the world to establish general criteria for the MS monitoring.

\section{References}

[1] Hajian-Tilaki, K. (2015) Metabolic Syndrome and Its Associated Risk Factors in Iranian Adults: A Systematic Review. Caspian Journal of Internal Medicine, 6, 51-61.

[2] Reaven, G.M. (1988) Banting Lecture 1988. Role of Insulin Resistance in Human Disease. Diabetes, 37, $1595-1607$. http://dx.doi.org/10.2337/diab.37.12.1595

[3] Moodley, J. (2011) Potentially Increasing Rates of Hypertension in Women of Childbearing Age and during Pregnancy - Be Prepared! Cardiovascular Journal of Africa, 22, 330-334. http://dx.doi.org/10.5830/CVJA-2010-074

[4] Okafor Christian, I. (2012) Prevalence of Metabolic Syndrome-Emerging Data from Africa. Indian Journal of Endocrinology and Metabolism, 16, 56-66.

[5] Balkau, B., Charles, M.A., Drivsholm, T., et al. (2002) Frequency of the WHO Metabolic Syndrome in European Cohorts, and an Alternative Definition of an Insulin Resistance Syndrome. Diabetes \& Metabolism, 28, 364-376.

[6] Panagiotakos, D.B., Pitsavos, C., Das, U.N., et al. (2007) The Implications of Anthropometric, Inflammatory and glycaemic control Indices in the Epidemiology of the Metabolic Syndrome Given by Different Definitions: A Classification Analysis. Diabetes, Obesity and Metabolism, 9, 660-668. http://dx.doi.org/10.1111/j.1463-1326.2006.00640.x

[7] Kahn, R., Buse, J., Ferrannini, E., et al. (2005) The Metabolic Syndrome: Time for a Critical Appraisal: Joint Statement from the American Diabetes Association and the European Association for the Study of Diabetes. Diabetes Care, 28, 2289-2304. http://dx.doi.org/10.2337/diacare.28.9.2289

[8] Expert Panel on Detection, Evaluation, and Treatment of High Blood Cholesterol in Adults (2001) Executive Summary of the Third Report of the National Cholesterol Education Program Expert Panel on Detection, Evaluation, and Treatment of High Blood Cholesterol in Adults (Adult Treatment Panel III). JAMA, 285, 2486-2497. http://dx.doi.org/10.1001/jama.285.19.2486

[9] National Cholesterol Education Program Expert Panelon Detection, Evaluation, and Treatment of High Blood Cholesterol in Adults (Adult Treatment Panel III). NIH Publication No. 01-3670, May 2001 www.nhlbi.nih.gov/files/docs/.../atp3xsum.pdf

[10] Grundy, S.M., Brewer Jr., H.B., Cleeman, J.I., et al. (2004) Definition of Metabolic Syndrome: Report of the National Heart, Lung and Blood Institute/American Heart Association Conference on Scientific Issues Related to Definition. Circulation, 109, 433-438. http://dx.doi.org/10.1161/01.CIR.0000111245.75752.C6

[11] Hajian-Tilaki, K. (2015) Metabolic Syndrome and Its Associated Risk Factors in Iranian Adults: A Systematic Review. Caspian Journal of Internal Medicine, 6, 51-61.

[12] Magalhães, P., Capingana, D.P. and Mill, J.G. (2014) Prevalence of the Metabolic Syndrome and Determination of Optimal Cut-Off Values of Waist Circumference in University Employees from Angola. Cardiovascular Journal of Africa, 25, No. 1. http://dx.doi.org/10.5830/CVJA-2013-086

[13] Kassi, E., Pervanidou, P., Kaltsas, G. and Chrousos, G. (2011) Metabolic Syndrome: Definitions and Controversies. BMC Medicine, 9, 48.

[14] Ford, E.S., Giles, W.H. and Dietz, W.H. (2002) Prevalence of the Metabolic Syndrome among US Adults: Findings from the Third National Health and Nutrition Examination Survey. Journal of the American Medical Association, 287, 356-359. http://dx.doi.org/10.1001/jama.287.3.356 
[15] Bartha, J.L., Bugatto, F.G., Macías, R.F., González, N.L., Delgado, R.C. and Vivancos, B.H. (2008) Metabolic Syndrome in Normal and Complicated Pregnancies. European Journal of Obstetrics \& Gynecology and Reproductive Biology, 137, 178-184. http://dx.doi.org/10.1016/j.ejogrb.2007.06.011

[16] Retnakaran, R., Qi, Y., Sermer, M., Connelly, P.W., Zinman, B. and Hanley, A.J.G. (2008) Isolated Hyperglycemia at 1 Hour on Oral Glucose Tolerance Test in Pregnancy Resembles Gestational Diabetes Mellitus in Predicting Postpartum Metabolic Dysfunction. http://care.diabetesjournals.org

[17] Teixeira, C.S.M. (2009) Metabolic Syndrome in Pregnancy as Predictor of Adverse Obstetric and Neonatal Outcomes. Dissertation (Master in Medicine), Institute of Biomedical Sciences Abel Salazar, University of Porto, Portugal. http://www.icbas.up.pt/biblioteca/images/.../boletim\%20bibliogrfico03.pdf

[18] Chatzi, L., Plana, E., Daraki, V., Karakosta, P., Alegkakis, D., Tsatsanis, C., Kafatos, A., Koutis, A. and Kogevinas, M. (2009) Metabolic Syndrome in Early Pregnancy and Risk of Preterm Birth. American Journal of Epidemiology, 170, 829-836. http://dx.doi.org/10.1093/aje/kwp211

[19] Chatzi, L., Plana, E., Pappas, A., Alegkakis, D., Karakosta, P., Daraki, V., Vassilaki, M., Tsatsanis, C., Koutis, A. and Kogevinas, M. (2009) The Metabolic Syndrome in Early Pregnancy and Risk of Gestational Diabetes Mellitus. Diabetes \& Metabolism, 35, 490-494. http://dx.doi.org/10.1016/j.diabet.2009.07.003

[20] Bartha, J.L., Marín-Segura, P., Gonzáles, N.L., Wagner, F., Aguilar-Diosdado, M. and Hervias-Vivancos, B. (2007) Ultrasound Evaluation of Visceral Fat and Metabolic Ris Factors during Early Pregnancy. Obesity, 15, 2233-2239.

[21] Bartha, J.L., Bugatto, F.G., Macías, R.F., González, N.L., Delgado, R.C. and Vivancos, B.H. (2008) Metabolic Syndrome in Normal and Complicated Pregnancies. European Journal of Obstetrics \& Gynecology and Reproductive Biology, 137, 178-184.

[22] Negrato, C.A., Jovanovic, L., Tambascia, M.A., Calderon Ide, M., Geloneze, B., Dias, A., et al. (2008) Mild Gestational Hyperglycaemia as a Risk Factor for Metabolic Syndrome in Pregnancy and Adverse Perinatal Outcomes. Diabetes/Metabolism Research and Reviews, 24, 324-330. http://dx.doi.org/10.1002/dmrr.815

[23] BO, S., Menato, G., Gallo, M.L., Bardelli, C., Lezo, A., Signorile, A., et al. (2004) Mild Gestational Hyperglycemia, the Metabolic Syndrome and Adverse Neonatal Outcomes. Acta Obstetricia et Gynecologica Scandinavica, 83, 335340. http://dx.doi.org/10.1111/j.0001-6349.2004.00314.X

[24] Noussitou, P., Monbaron, D., Vial, Y., Gaillard, R.C. and Ruiz, J. (2005) Gestational Diabetes Mellitus and the Risk of Metabolic Syndrome: A Population-Based Study in Lausanne, Switzerland. Diabetes \& Metabolism, 31, 361-369. http://dx.doi.org/10.1016/S1262-3636(07)70205-7

[25] Nicholl, A., du Heaume, M., Mori, T.A., Beilin, L.J., Oddy, W.H., Bremner, A.P. and O’Sullivan, T.A. (2014) Higher Breakfast Glycaemic Load Is Associated with Increased Metabolic Syndrome Risk, Including Lower HDL-Cholesterol Concentrations and Increased TAG Concentrations, in Adolescent Girls. Journal of Nutrition, 20, 1-10.

[26] Drebes, C., Hentschke, M., Cioffi, L., Furlanetti, T., da Costa, B.E.P., de Figueiredo, C.E.P. and Gadonski, G. (2014) Hypertensive Disease Pregnancy and Metabolic Syndrome: Disponivel Metoprolol. www.pucrs.br/./70586-CHRISTIANVALMORENGSTERDREBES.pdf

[27] Al-Nasiry, S., Ghossein-Doha, C., Polman, S., Lemmens, S., Scholten, R., Heidema, W., Spaan, J. and Spaanderman, M. (2014) Metabolic Syndrome after Pregnancies Complicated by Pre-Eclampsia or Small for Gestational Age: A Retrospective Cohort. BJOG: An International Journal of Obstetrics \& Gynaecology, 47, 54-55. http://dx.doi.org/10.1111/1471-0528.13117

[28] Liu, J., Laditka, J.N., Mayer-Davis, E.J. and Pate, E.R. (2008) Does Physical Activity during Pregnancy Reduce the Risk Gestacional Diabetes among Previously Inactive Women? Birth, 35, 188-195.

[29] Hou, R.L., Jin, W.Y., Chen, X.Y., Jin, Y., Wang, X.M., Shao, J. and Zhao, Z.Y. (2014) Cord blood C-Peptide, Insulin, HbA1c, and Lipids Levels in Small- and Large-for-Gestational-Age Newborns. Medical Science Monitor, 20, 20972105.

[30] Knopp, R.H. (1997) Hormone-Mediated Changes in Nutrient Metabolism in Pregnancy: A Physiological Basis for Normal Fetal Development. Annals of the New York Academy of Sciences, 817, 251-271. http://dx.doi.org/10.1111/j.1749-6632.1997.tb48212.x

[31] Montenegro, Barbosa, C.A., Filho, R. and de Rezende, J. (2008) Fundamental Obstetrics. Guanabara Koogan, Rio de Janeiro, 550-607.

[32] Gaspar, C.N. and do Nascimento, M. de J.P. (2004) Effects of Maternal Diabetes for Newborn. Nursing Journal, UNISA, 5, 57-61.

[33] Maganra, A.C. (2002) Diabetes Repercussion in the Fetus and New-Born. Brazilian Journal of Gynecology and Obstetrics, 13, 158-162.

[34] Maganha, C.A., Vanni, D.G.B.S., Bernardini, M.A. and Zugaib, M. (2003) Treatment of Gestational Diabetes Mellitus. Journal of the Brazilian Medical Association, 49, 330-334. 